\title{
The Effect of Initial Visual Acuity on Visual Prognosis in Low Vi- sion Aid and Rehabilitation Cases
}

\author{
Deniz Altinbay ${ }^{1}$ and Fatih Mehmet ADIBELLI, ${ }^{1 *}$ \\ ${ }^{1}$ Specialist, Niv Eye Center, Adana, Turkey \\ ${ }^{2}$ Assist. Prof. of Ophthalmology, Faculty of Medicine, Harran University, Turkey
}

*Corresponding author: Assist. Prof. Fatih Mehmet ADIBELLI, Department of Ophthalmology, Faculty of Medicine, Harran University, Osmanbey Kampusu, 63100 Sanliurfa, Turkey, Tel: +90-414318-3000, Fax: +90-4143183190, E-mail: fadibelli@gmail.com

\begin{abstract}
Purpose: To analyze the initial visual acuities of cases referred to our clinic due to low vision and the effect on visual prognosis.

Materials and methods: A retrospective evaluation was carried out on 869 eyes of 464 patients who were referred to our center due to low vision between December 2010 and May 2015. Distance acuities of the patients were measured with a distant vision chart prepared for patients with low vision, and the near acuities were measured with a Jaeger near vision chart. Patients with logMAR $\geq 0.5$ [snellen $\leq 20 / 63$ ] visual acuity were included in the study. Cases were separated into 4 groups according to initial distant acuity and 3 groups according to the initial near acuity values. In the statistical analysis, a value of $p<0.05$ was accepted as statistically significant

Results: The mean distant acuity of the cases was found to be $0.13 \pm 0.11$ (Snellen) (mean logMAR 0.9) and $0.55 \pm 0.29$ (Snellen) (mean logMAR 0.3) respectively before and after the low vision aid (LVA) examination. The mean near acuity of the cases was $\mathrm{J} 13.93 \pm 4.21$ (mean logMAR 0.8) and $\mathrm{J}$ $7.76 \pm 4.51$ (mean logMAR 0.4 ) respectively before and after the LVA. Initial distant visual acuity was logMAR $>1.3$ [Snellen $<20 / 400$ ] in $14 \%$, logMAR 1.3-1.0 [snellen 20/400-20/200] in $48 \%$, logMAR 0.7-1.0 [snellen 20/200-20/100] in 22\% and logMAR $<0.7$ [ $>$ snellen 20/100] in $16 \%$ of the cases. In total, it was seen that the visual acuity of $62 \%$ of the cases was at the level of "legally blind" (logMAR $\geq 1.0$ ) [snellen $\leq 20 / 200$ ]. The distant and near visual acuities before LVA were determined as the factors that had the greatest effect on the improvement of distant and near acuities of the patients.

Conclusion: The visual acuity at the time of application is the primary factor affecting LVA success. In this study, the visual acuity of the cases referred to our center for LVA was evaluated as quite low, sufficient time could not be allocated to cases due to intense polyclinic conditions and patients were referred late. With earlier referral, it would be possible to enable patients to remain more self-sufficient.
\end{abstract}

\section{Keywords}

Low vision aid and rehabilitation, Visual acuity, LVA

\section{Introduction}

Low Vision Aid (LVA) devices which are used to enable patients to use their remaining sight in the most efficient way in low vision aid and rehabilitation and to reintroduce them to society as independent individuals, provide vision improvement in patients whose sight cannot be improved through standard procedures [1-3].

Low vision aid devices and rehabilitation programs vary according to diagnosis, age, visual acuity, educational status and implemented magnifying power and all these factors affect the success of patients in using the devices provide $[2,4-9]$. Initial visual acuity (VA) is the primary factor affecting LVA success $[2,3]$.

In this study, an evaluation was made of the VA at the time of presentation of patients who were referred to our center due to low vision and the effect of initial VA on visual prognosis.

\section{Material and Methods}

A retrospective evaluation was carried out on 869 eyes of 464 patients who were referred to our center due to low vision between December 2010 and May 2015. Optical correction, biomicroscopic anterior and posterior segment examination and intraocular pressure measurements were applied to all patients.

The diagnoses of the patients referred for low vision aid were as follows:

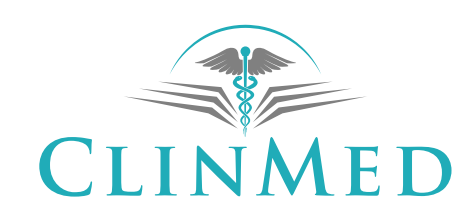

INTERNATIONAL LIBRARY
Citation: Altinbay D, Adibelli FM (2018) The Effect of Initial Visual Acuity on Visual Prognosis in Low Vision Aid and Rehabilitation Cases. Int J Ophthalmol Clin Res 5:087. doi.org/10.23937/2378-346X/1410087 Received: June 01, 2016: Accepted: May 03, 2018: Published: May 05, 2018

Copyright: (C) 2018 Altinbay D, et al. This is an open-access article distributed under the terms of the Creative Commons Attribution License, which permits unrestricted use, distribution, and reproduction in any medium, provided the original author and source are credited. 
$33.98 \%$ of age-related macular degeneration, $14.41 \%$ of retinitis pigmentosa, $12.47 \%$ of diabetic retinopathy, $9.46 \%$ of Stargardt Disease, $9.46 \%$ of nystagmus, $6.45 \%$ of optic atrophy, $4.73 \%$ of glaucoma, $2.80 \%$ of albinism and nystagmus, $2.37 \%$ of degenerative myopia, $1.72 \%$ of visual pathways disorders, $2.15 \%$ of other diseases.

Following the correction of distant VA and refractive errors of the patients, distance acuity was measured with a distant vision chart (Test Charts for Low Vision Patients, ZEISS, Germany), which was specially prepared for patients with low vision, and near acuity was measured with the Jaeger $(\mathrm{J})$ near vision chart.

\section{Low vision aid (LVA)}

LVA devices, including highly spherical supplementary near vision glasses, highly spherical supplementary prismatic glasses and special filtered glasses were used in the low vision aid examination. The devices used in the LVA tests were Zeiss (Germany), Schweizer (Germany) and Escenbach (Nürnberg, GERMANY), Galilei and Kepler telescopic systems.

Patients with VA $\log M A R \geq 0.5$ [ $\leq 20 / 63]$ ) were included in the study. Patients were divided into 4 groups according to the VA values. Group 1 comprised patients with initial VA of logMAR > 1.3 [<20/400], Group 2 logMAR 1.3 - logMAR 1.0 [20/400-20/200], Group 3 logMAR 1.0 - logMAR 0.7 [20/200-20/100]) and Group 4 < logMAR 0.7 [> 20/100] Patients were divided into 3 groups according to the near VA values. Near VA Group I included patients with initial values of J16 - J19, Group II J9 - J15 and Group III < J9.

In this study, evaluation was made of the VA at the time of presentation of patients referred to our center because of low vision and the effect of initial VA on the visual prognosis.

\section{Statistical analysis}

The SPSS 20.0 package program was used in the analysis of the data. Chi-Square test statistics were used in the comparison of categorical data between the groups.
Conformity of the numerical measurements to normal distribution was tested with the Kolmogrov-Smirnov test. In the general comparison of the numerical measurements of more than two groups, One Way Variance Analysis was used in cases where the assumptions were supported and the Kruskal Wallis test in cases where the assumptions were not supported. In the pairwise comparison of the groups, the Bonferroni, Scheffe, and Tamhane tests were used according to whether or not the intragroup variances were homogeneous when the assumptions were supported. The Mann Whitney $U$ test with Bonferroni correction was used in the pairwise comparison of the groups, when the assumptions were not supported. Linear Regression was applied to determine the measurements most affecting the distant or near VA alteration value. A value of $p<0.05$ was accepted as statistically significant in all tests.

\section{Results}

The cases included in the study comprised 300 males (65\%) and 164 females (35\%) with a mean age of 49.9 \pm 25.7 (range, 5-93 years). Unilateral evaluation was made in 59 of 464 patients and bilateral in 405 . The visual acuity of all cases ranged between 0.01 and 0.30 . The mean VA of the cases before the low vision aid was $0.13 \pm 0.11$ (Snellen 0.01-0.3) (mean logMAR 0.9) and $0.55 \pm 0.29$ (Snellen between 0.01-1.00) after the LVA. The mean near visual acuity was J13.93 \pm 4.21 (between J3-J19) (mean logMAR 0.8) before the LVA and J7.76 \pm 4.51 (J1-J19) (mean logMAR 0.4) after LVA.

Initial distant visual acuities were $\log M A R>1.3$ [< 20/400] in 14\%, logMAR 1.3-logMAR 1.0 [20/40020/200] in 48\%, logMAR 0.7- logMAR 1.0 (including logMAR 0.7) [20/200-20/100, including 20/100] in 22\% and $\log M A R<0.7$ [ $>20 / 100]$ in $16 \%$ of the cases (Table 1 ).

When all the cases included in the study were analyzed, it was seen that $87 \%$ of the cases had at least 2 standard orders (0.2 logMAR) distant visual acuity improvement.

When initial near visual acuities were analyzed, $45 \%$

Table 1: Distant vision degrees of patients before and after LVA. LVA: Low vision aid.

\section{The best of distant VA}

VA $<20 / 400$ (VA $>$ logMAR 1.3)

$20 / 200 \geq V A \geq 20 / 400(\log M A R \quad 1.0 \leq \mathrm{VA} \leq \log M A R \quad 1.3)$

$20 / 100 \geq V A>20 / 200(\log M A R 0.7 \leq V A<\log M A R 1.0)$

$\mathrm{VA}>20 / 100(\log M A R<0.7)$

Total

chi-square test, $p<0.001$; VA: Visual Acuity.

\begin{tabular}{|l|l|l|}
\hline Before LVA (\%) & After LVA (\%) & Total \\
\hline $65(\% 14)$ & $9(\% 1.9)$ & 74 \\
\hline $221(\% 47.6)$ & $23(\% 5)$ & 244 \\
\hline $103(\% 22.2)$ & $43(\% 9.3)$ & 146 \\
\hline $75(\% 16.2)$ & $389(\% 83.8)$ & 464 \\
\hline $464(\% 100)$ & $464(\% 100)$ & 928 \\
\hline
\end{tabular}

Table 2: Near vision degrees of patients before and after LVA.

\begin{tabular}{|l|l|l|l|}
\hline The best of near VA (jaeger) & Before LVA (\%) & After LVA (\%) & Total \\
\hline $16 \leq \mathrm{VA} \leq 19$ & $209(\% 45)$ & $53(\% 11.3)$ & 262 \\
\hline $9 \leq \mathrm{VA}<16$ & $206(\% 44.4)$ & $132(\% 28.4)$ & 338 \\
\hline $1 \leq \mathrm{VA} \leq 7$ & $49(\% 10.6)$ & $279(\% 60.4)$ & 328 \\
\hline Total & $464(\% 100)$ & $464(\% 100)$ & 928 \\
\hline
\end{tabular}

LVA: Low Vision Aid; VA: Visual Acuity. 
of the cases were between J16 and J19 (including J16 and J19), $44.4 \%$ were between J9 and J16 (including J9) and $10.6 \%$ were below J9) (Table 2).

In cases with distant VA of $\log M A R>1.3[<20 / 400]$ before LVA, it was determined that the improvement of near VA was lower proportionately, although the improvement of distant VA was higher $(p<0.001)$. Finally, it was seen that the cases with higher distant VA had higher distant and near VA alteration ratio comparing to the other groups $(p<0.001)$.

When age, gender, diagnosis, and the distant and near VA values before LVA were analyzed, it was seen that the factor which affected the improvement of distant and near VA was the distant and near VA values before LVA. While the rate of distant VA improvement in cases with better initial distant VA and worse initial near VA was low, it was seen that near VA improvement rate in these cases was high $(p<0.001)$ (Figure 1 and Figure 2).

The most increased near VA (10-13 increase) was found in the group of the worst initial near VA before LVA (J16 $\leq$ VA $\leq 19)$. The group with the least increase in near VA was found to be in the group with good initial near VA before LVA (J1 $\leq$ VA $\leq$ J8) (Figure 3 ).

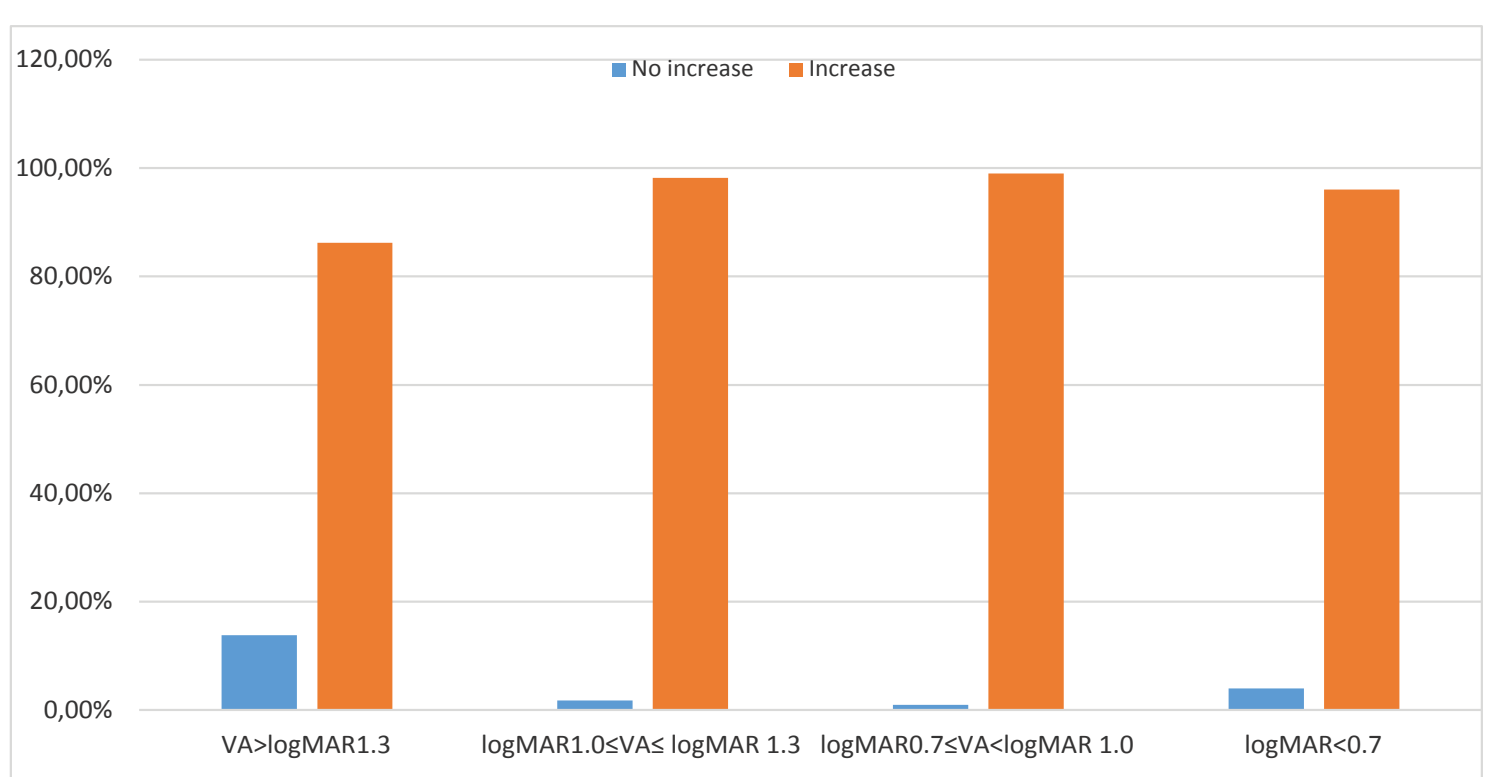

Figure 1: The ratios of benificial effects of LVA devices according to distant vision degrees of patients before LVA (The comparision of patients that have increase in distant vision degrees and haven't in the form of percentage). LVA: Low Vision Aid; VA: Visual Acuity.

No increase Increase

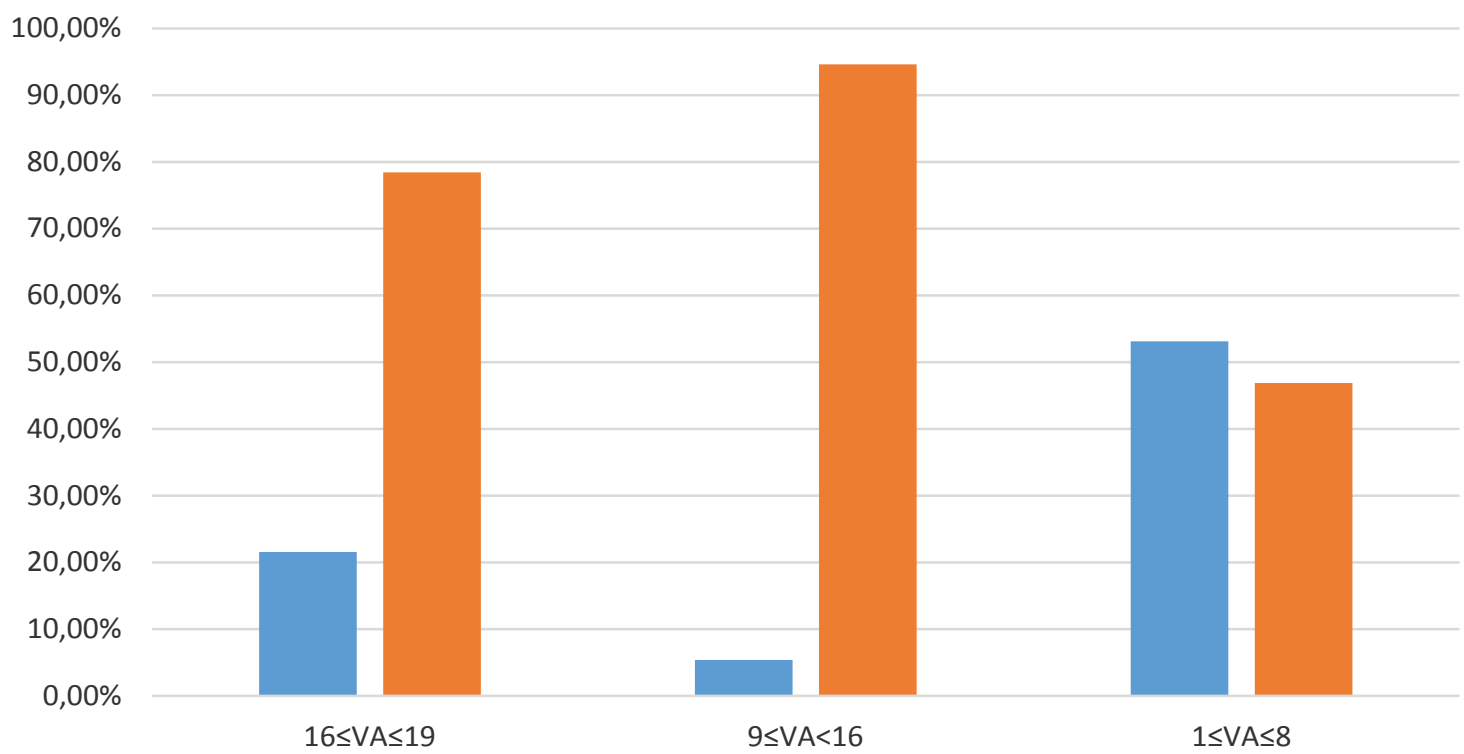

Figure 2: The ratios of benificial effect of LVA devices according to near vision degrees of patients before LVA (The comparison of patients that have increase in near vision degres and haven't in the form of percentage). LVA: Low Vision Aid; VA: Visual Acuity. 
No increase $\quad$ 1-4 line increase 5-9 line increase $\quad$ 10-13 line increase

$70,00 \%$

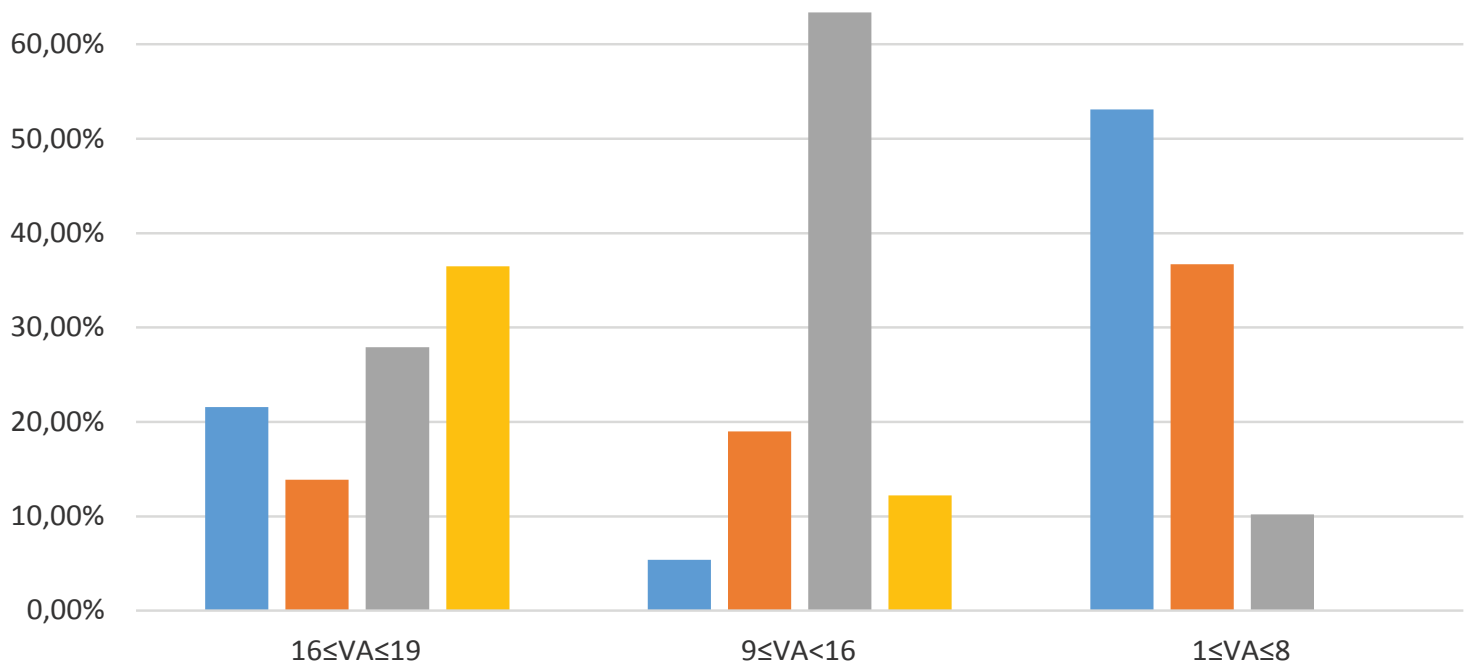

Figure 3: The ratios of benificial effect of LVA devices according to near vision degrees of patients before LVA (The comparison of patients that have increase in near vision degres and haven't in the form of of percentage). LVA: Low Vision Aid; VA: Visual Acuity.

There was a weak correlation between age and distant VA improvement rate, in other words, the rate of distant VA improvement rate fell with increasing age $(r$ $=-0.100, p=0.031)$.

\section{Discussion}

Low vision rates vary between $0.23 \%$ and $3.5 \%$ according to the level of development in different countries [10-15]. The rate of low-vision patients gradually increases with an increasing elderly population and will therefore continue to be a growing problem for ophthalmologists in the future [16].

There are many factors that affect the success of low vision aid and rehabilitation. The initial VA of the cases at time of presentation at our low vision center was a leading factor affecting the success of LVA $[2,3]$.

In various studies, it has been stated that LVA success and the rates of the use of telescopic glasses in cases with high VA before LVA were high $[2,3,7]$. Therefore, the initial distant and near VA values of patients at the time of presentation to such centers are crucial.

In the current study, it was seen that the distant VA was over logMAR $1.3[20 / 400]$ in $14 \%$ and between logMAR 1.3 and logMAR 1.0 [20/200] in $48 \%$ of the cases who presented at our center for LVA examination, in other words, $62 \%$ of the cases in total were at the level of 'legally blind'. Most of the cases had been referred for LVA examination in a period when their VA greatly decreased.

The mean distant VA of the cases included in the study were found to be $0.13 \pm 0.11$ (Snellen) (mean logMAR 0.9) before the LVA examination and $0.55 \pm 0.29$ (Snellen) (mean logMAR 0.3) after the LVA examination.
When all the cases were analyzed, it was seen that $87 \%$ of the cases had a VA improvement of at least 2 standard orders (0.2 logMAR).

In the group with good initial distant VA, the rate of visual improvement is less than the rate of improvement in the group with low initial distant VA. It should not be forgotten that this situation is a proportional concept and does not mean that the final visual acuity is better in the group with low initial distant VA.

It is known that people with a distant VA level lower than logMAR 1.0 [> 20/200] do not have orientation problems in a familiar environment [17]. When all the cases included in the study were analyzed, it was seen that $62 \%$ were classified as 'legally blind' (logMAR 1.0 and over) $[\leq 20 / 200]$ and this rate fell to $7 \%$ after the LVA examination. The distant VA of $84 \%$ of the cases after LVA was observed to be lower than logMAR 0.7 [ $>20 / 100$ ], and the VA of $93 \%$ in total was lower than logMAR 1.0 [> 20/200].

Individuals with near VA of up to logMAR 0.4 [20/50] (Jaeger 7) are reported to be able to read a newspaper [17]. The mean near VA of the cases included in the study before LVA was J13.93 \pm 4.21 . The mean near VA rate after LVA was J7.76 \pm 4.51 (between J1-J19) (mean IogMAR 0.4). While $89 \%$ of the cases had near VA of a level that they could not read a newspaper at the time of presentation, this rate fell to $40 \%$ after LVA examination. $60 \%$ of the cases attained a level of near VA to be able to read a newspaper again. When all the cases included in the study were analyzed, at least 2 orders (Jaeger) of visual improvement were observed in $77 \%$ of the cases. In a study by Nilsson, et al. it was shown that the rate of being able to read a newspaper increased from $0.8 \%$ to $92.5 \%$ [2]. Ji, et al. reported success in near 
VA improvement in $87 \%$ and Temel, et al. in $86.7 \%$ of cases $[7,18]$.

As telescopic glasses, which are given to patients to provide distant visual improvement, are complex devices, they require good adaptation and experienced personnel $[2,7,19-21]$. The efficiency and success of the LVA system implemented can be demonstrated with objective criteria such as improvement in distant and near visual activities and reading rate $[2,4,6,22]$.

In several previous studies it has been reported that the usage rate of telescopic glasses and LVA success were high in cases with high VA before LVA, and the use of telescopic glasses decreased with increasing age $[2,3,5,7]$.

In the current study, it was found that the factors most affecting distant and near VA improvement were the distant and near VA values before LVA. Of the cases referred to the low vision center for visual aid, $62 \%$ were classified as legally blind with a VA of logMAR 1.0 and above [ $\leq 20 / 200]$. In addition, a weak negative correlation was determined between age and the VA improvement rate as the VA improvement rate decreased with increasing age.

The initial distant and near VA of the low vision patients are important parameters affecting LVA success. Thus, low vision patients can benefit more from LVA when they apply to LVA centers earlier.

In a study involving 143 adult low-vision patients, it was reported that many obstacles to reaching LVA centers. Although $97.1 \%$ of the patients suffered that they had difficulty in reading, only $11 \%$ of the patients were referred to the LVA centers. In this study, it was concluded that the ophthalmology community should be better trained to be directed to LVA centers for patients with irreversible visual impairment [23].

Kumar, et al. studied medical records 14,938 registered patients and they showed that 499 of these patients did not benefit from the LVA rehabilitation service. The reason for this was found to be either not guided by the physician or misguided (39\%), LVA was not accepted by the patient (53\%), loss of appointment tables (4.5\%) and hospital departure (3.5\%) [24].

Bakbak, et al. reported that patients who applied for LVA were in the terminal period of their illness and the visual acuity was extremely low [25]. It has been reported that when the referral is delayed of individuals with low vision to the necessary centers for rehabilitation, these individuals are likely to develop depression and lose motivation for possible rehabilitation [26].

779 patients from 28 clinical centers in the USA were enrolled in the Three-Year Low Vision Rehabilitation Results Study (LVROS) from 2008 to 2011. These patients were administered the visual function questionnaire Activity Inventory (Al) in order to measure general visual abilities and visual abilities in 4 functional areas (reading, mobility, visual motor function and visual information processing). These Patients were administered Geriatric Depression Scale to measure psychological, cognitive and physical health conditions and physical functioning questionnaire for telephone interview and health survey for Cognitive Status. Correlation between LogMAR visual acuity and basic visual ability and all functions was observed. Visual acuity has been found to be the strongest determinant of visual ability and reading ability and has also been found to have a significant independent effect on other functional areas [27].

\section{Conclusion}

The visual acuity at the time of presentation is the primary factor affecting LVA success. In the current study, the VA of cases referred to our center for LVA was evaluated as quite low, sufficient time could not be allocated to cases in intense polyclinic conditions and patients were referred late. With earlier referral, it would be possible to enable patients to become more independent.

\section{References}

1. Raasch TW, Leat SJ, Kleinstein RN, Bullimore MA, Cutter GR (1997) Evaluating the value of low-vision services. J Am Optom Assoc 68: 287-295.

2. Nilsson UL, Nilsson SE (1986) Rehabilitation of the visually handicapped with advanced macular degeneration. A follow-up study at the Low Vision Clinic, Department of Ophthalmology, University of Linköping. Doc Ophthalmol 62: 345-367.

3. Humphry RC, Thompson GM (1986) Low vision aids--evaluation in a general eye department. Trans Ophthalmol Soc U K 105: 296-303.

4. Wu DZ, Wu L, Chang FX, Jin C, Padula W (1995) Visual rehabilitation in low vision patients with aging macular degeneration. J Am Optom Assoc 66: 39-41.

5. Mcllwaine GG, Bell JA, Dutton GN (1991) Low vision aids-is our service cost effective? Eye (Lond) 5: 607-611.

6. Leat SJ, Rumney NJ (1990) The experience of a university-based low vision clinic. Ophthalmic Physiol Opt 10: 8-15.

7. Temel A (1989) Low vision aids (evaluation of 185 patients). Ophthalmic Physiol Opt 9: 327-331.

8. Lovie-Kitchin JE, Whittaker SG (1999) Prescribing near magnification for low vision patients. Clin Exp Optom 82: 214-224.

9. Idil A, Ozen M, Atak N, Elhan A, Pehlivan S (2011) Validity and reliability study of Turkish version on low vision with quality of life questionnaire. Int J Ophthalmol 4: 546-551.

10. Strong JG, Pace RJ, Plotkin AD (1988) Low vision services: a model for sequential intervention and rehabilitation. Can $\mathrm{J}$ Public Health 79: S50-S54.

11. Limburg H, Espinoza R, Lansingh VC, Silva JC (2015) Functional low vision in adults from Latin America: findings from population-based surveys in 15 countries. Rev Panam Salud Publica 37: 371-378.

12. Tong X, Zhao R, Zou H, Zhu J, Wang J, et al. (2011) A prevalence investigation of blindness and vision impairment in 
2009 in older adults of Dachang Blocks of Baoshan District, Shanghai, China. Zhonghua Yan Ke Za Zhi 47: 785-790.

13. Entekume G, Patel J, Sivasubramaniam S, Gilbert CE, Ezelum CC, et al. (2011) Prevalence, causes, and risk factors for functional low vision in Nigeria: results from the national survey of blindness and visual impairment. Invest Ophthalmol Vis Sci 52: 6714-6719.

14. Maberley DA, Hollands $H$, Chuo J, Tam G, Konkal J, et al (2006) The prevalence of low vision and blindness in Canada. Eye (Lond) 20: 341-346.

15. Dowie A (1988) Management and practice of low vision acuity. The Eastern Press, London, 11-48.

16. Kraut $\mathrm{J}$, McCabe $P$ (2000) Low vision: what is it and who is affected. Principles and Practice of Ophthalmology 6: 53955396.

17. Egrilmez S EDE, Akkin C, Kaskaloglu M, Yagci A (2004) A new Turkish near reading chart which covers international standards. Turk J Ophtalmol 34: 404-412.

18. Ji YH, Park HJ, Oh SY (1999) Clinical effect of low vision aids. Korean J Ophthalmol 13: 52-56.

19. Bailey I (1994) Telescopes for the visually impaired. In: Colenbrander A, Fletcher DC, Low Vision and Rehabilitation, Ophthalmology Clinics of North America. 169-175.

20. Chan IM, Friedman GR, Ho PC, Tolentino FI (1984) Low-vi- sion aids for patients with suboptimal vision after closed vitrectomy for diabetic vitreous hemorrhage. Ophthalmology 91: 458-460.

21. Nilsson UL (1988) Visual rehabilitation of patients with advanced stages of glaucoma, optic atrophy, myopia or retinitis pigmentosa. Doc Ophthalmol 70: 363-383.

22. Kalloniatis M, Johnston AW (1990) Visual characteristics of low vision children. Optom Vis Sci 67: 38-48.

23. Coker MA, Huisingh CE, McGwin G Jr, Read RW, Swanson MW, et al. (2018) Rehabilitation Referral for Patients With Irreversible Vision Impairment Seen in a Public Safety-Net Eye Clinic. JAMA Ophthalmol 136: 400-408.

24. Kumar H, Monira S, Rao A (2016) Causes of Missed Referrals to Low-Vision Rehabilitation Services: Causes in a Tertiary Eye Care Setting. Semin Ophthalmol 31: 452-458.

25. Bakbak B, Gedik S, Guzel H (2011) Application and our clinical results of low vision aids. Ret-Vit 19: 246-249.

26. Finestone S, Gold SS (1959) The role of the ophthalmologist in the rehabilitation of blind patients: American Foundation for the Blind.

27. Goldstein JE, Chun MW, Fletcher DC, Deremeik JT, Massof RW, et al. (2014) Low Vision Research Network Study Group. Visual ability of patients seeking outpatient low vision services in the United States. JAMA Ophthalmol 132: 1169-1177. 